\title{
CONSIDERAÇÕES EM TORNO DO DIAGNOSTICO DE 2 CASOS DE DOENÇA DE NICOLAS e FAVRE
}

\author{
D. do LUIZ BAPTISTA \\ (Interno-chefe da Liga de combate à sifilis)
}

Tomando como assunto de tése inaugural, por sabia sugestão do Prof. Dr. Aguiar Pupo, o estudo de Doença de Nicolas e Favre, pareceu-nos, interessante, trazer-vos aqui, 2 dos 36 casos observados que temos, pelas dificuldades de diagnostico. Deixaremos portanto de lado quaesquer considerações que a elas não se refiram.

\section{Observação N.॰ 9 (30-12-32)}

S.A.L. 26 anos - preto - solteiro - lavrador - brasileiro residente e procedente de Biriguy (São Paulo)

\section{A - ANAMNESE}

Entrada: 30-12-32.

Queixa: Adenite inguinal direita, supurada, pouço doloroza.

Molestia atual: Está doente ha 67 dias. Sua molestia se iniciou por um nodulo pouco dolorozo, principalmente á palpação e á marchá, localizado na região inguinal direita, na arcada crural, ocupando - seu terço interno. Não houve lesão inicial patente.

Em 20 dias atingiu as dimensões maximas, aumentando-se a dôr e - rubôr. No fim de 30 dias teve supuração expontanea, dando saída á grande quantidade de pús cremôso. Desapareceram-se as dôres com a supuração. Concomitantemente ao aparecimento da adenite, sentiu mau estar, cefaléas, anorexia intensa, febre (tremores de frio, sudorése abundante), fortes dôres articulares. Os sintomas geraes desapareceram ao mesmo tempo que os sintomas agudos locaes, i. é, com a supuraçăo da adenite. Fez tratamentos caseiros, com infusão de raiz de planta desconhecida pelo paciente. Nấo sentiu melhoras. Procurou medico, que lhe receitou uma pomada, que pelas indicaçóes parece ser unguento mercurial. Não melhorou. Procuro-nos, então, 26-12.32 no Ambulatorio de Pele e Sifilis, por indicação de um sobrinho que pa- 


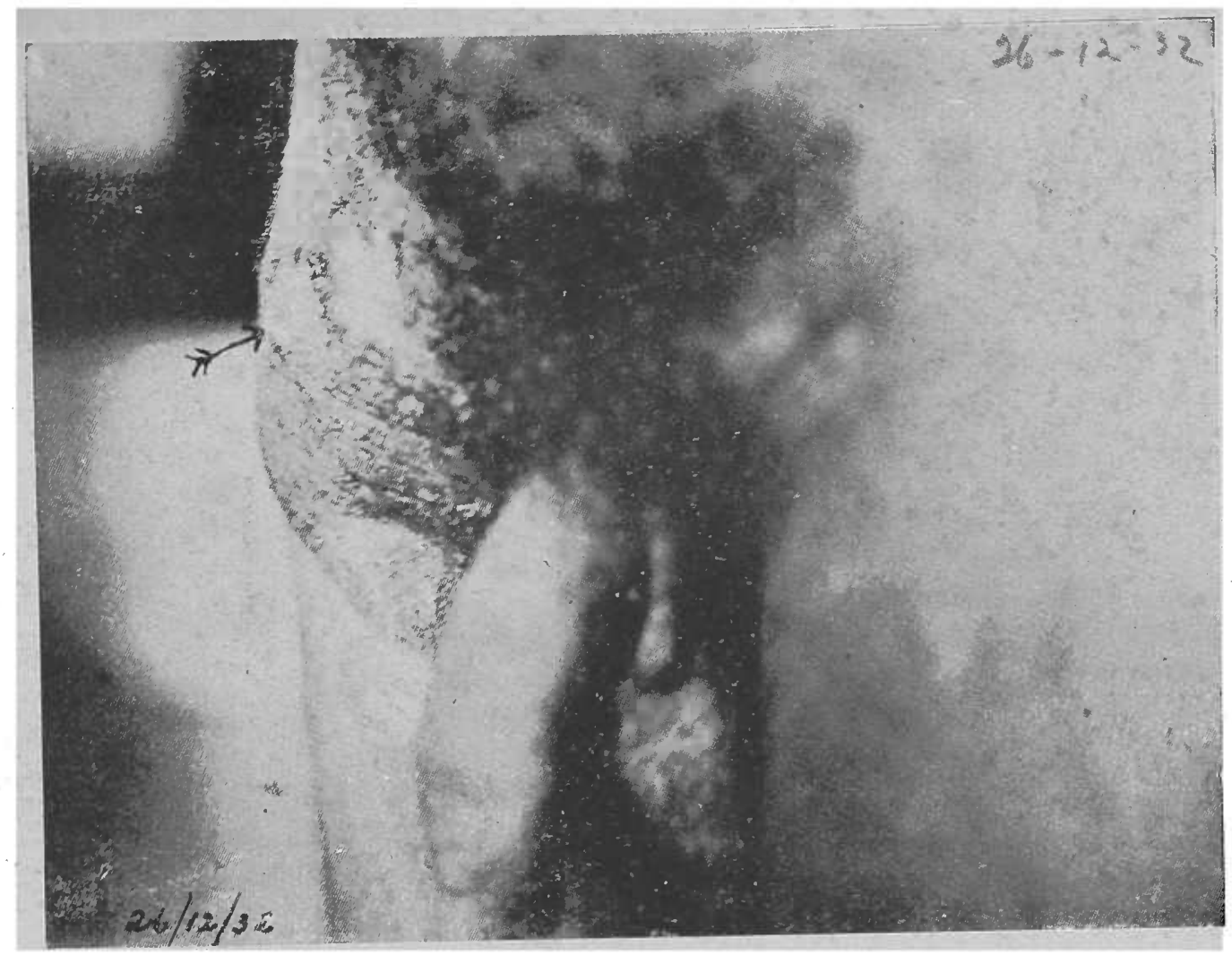

Fig. 1 - Fotografia em meio perfil, mostrando um: volumoso tumor da região inguinal direita, na data em que o paciente se nos apresentou á consulta (26-12-32)

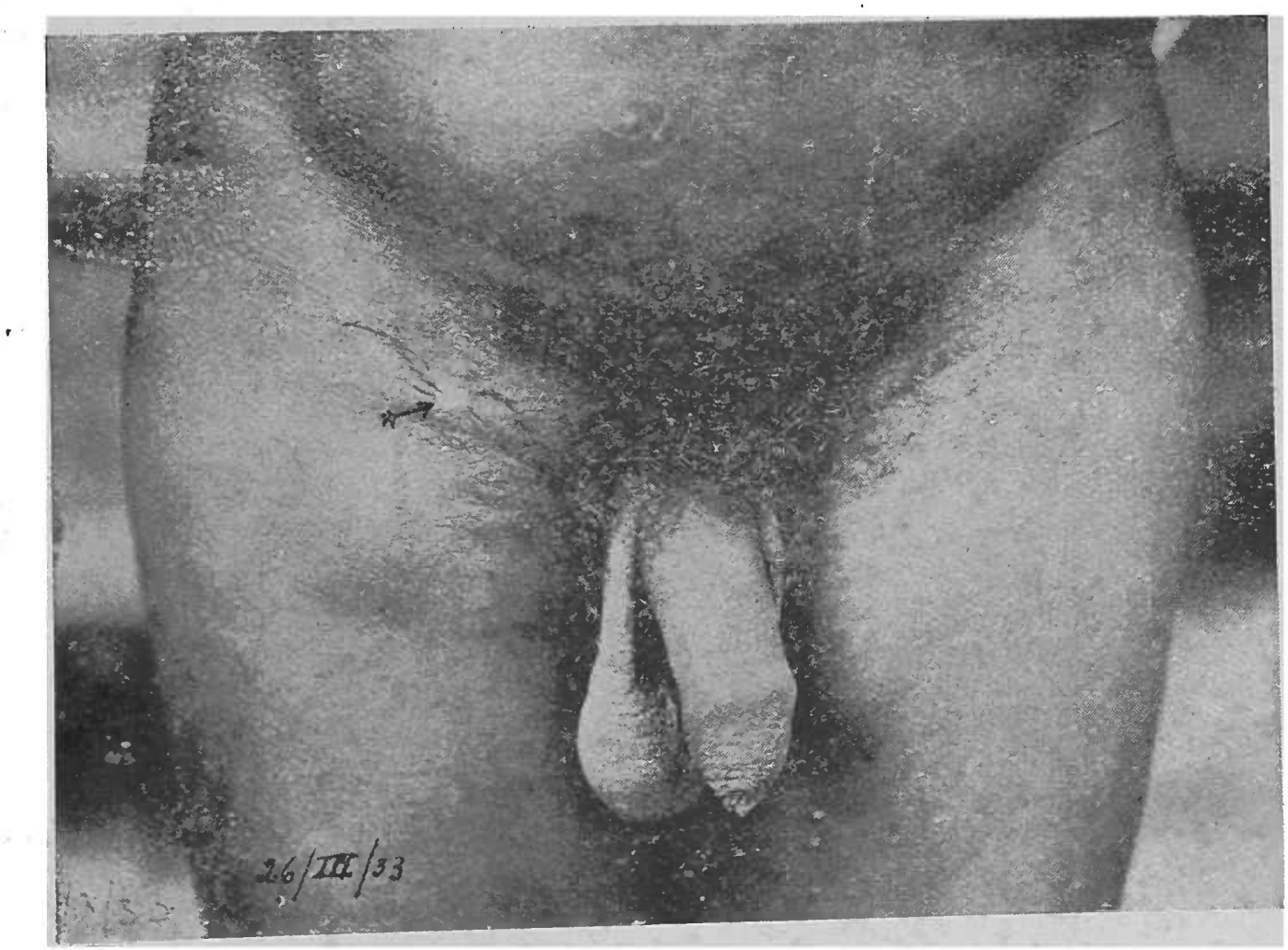

Fig. 2 - Mostra o aspecto da mesma região, apoz o tratamento. $N . B$. - A seta na fig. 1 indica a ulcera aberta, cuja descrição so encontra no texto desta observação; a fig. 2 indica a ulcera cicatrizada. 

dece do mesmo mal, estando este em tratamento no referido Ambulatorio.

Antecedentes pessoais e hereditarios: Em 1919 (?) teve a primeira molestia venérea : uma adenite bilateral, que após supuração, cedeu. Essa adenite bilateral não foi precedida, segundo a informaçâo do doente, de lesão inicial. Em 1923 teve gonorréa. Tratou-se com lavagens e diz, ter se curado. Depois da gonorréa só teve a doença atual.

Habitos: Bebia pinga moderadamente. Não fuma. Não abusa dos prazeres sexuaes.

Antecedentes hereditarios: sem interesse.

\section{B - EXAME OBJETIVO}

I) Inspeção geral do doente.

Estado geral abatido, relativamente nutrido, musculatura regularmente desenvolvida, paniculo adiposo escasso; peso antes da doença atual: 63 kilos. 'Pesava na data da observação : 59,5 kilos. Altura : 1,74 ms. Mucosas visiveis descoradas, pela seca, não apresentando circulação colateral, nem edema; sem signal de cicatriz. Ganglios linfaticos epitrocleanos não palpaveis; cervicaes posteriores palpaveis, infartados, duros não dolorosos; axilares com os mesmos caracteres que os cervicaes posteriores; não há tibialgia nem esternalgia. Não apresenta estigmas de lues hereditaria, a não ser abobada ogival.

Temperatura : 36,5 .

II) Exame de aparelhos, sistemas, orgãos e regiões.

Aparelho digestivo: boca - dentes mal conservados, apresentando algumas falhas. Lingua ligeiramente saburrosa, descorada, apresentando impressões dentarias.

Abdomen : baço e figado não palpaveis.

Aparelho respiratorio : normal.

Aparelho circulatorio: Apresentava o doente uma aritmia. Desdobramento da 2.a bulha audivel em todos os fócos. 1.a bulha ligeiramente soprosa no fóco mitral.

Electrocardiograma: alongamento do espaço PR.

Sistema nervoso: reflexos aquilianos exaltados.

Os demais reflexos tendinosos presentes e normais.

Reflexo cutaneo-plantar normal.

Aparelho visual: Pupilas iguaes, reagindo bem á luz e á acomodação. Reflexos consensuaes normaes. 
Aparelho uro-genital: dôres lombares. Nicturia.

Exame das regiōes, inguino-crural e inguino-abdominal: - Pela inspeção nota-se um tumor volumoso, das dimensões duma grande laranja; a pele que recobre está ligeiramente rubefeita, distendida, aderente ao plano subjacente, que é u'a massa ganglionar dura, bosselada.

Essa massa tumoral ocupa toda a região interna da arcada crural e região inguino-crural, principalmente na sua porção superior e interna.

Pela palpação a região não é doloroza. É como dissemos, ligeiramente rubefeita, apresentando ligeira elevação de temperatura, comparada á região homologa.

Os ganglios da região inguino-abdóminal não estão tomados. Ao nivel do terço medio da arcada crural existe uma ulcera de forma ovalar, de bordos regulares, infiltrados, descolados. A ulcera é ligeiramente excavada apresentando o fundo vermelho-presunto, levemente granulozo. Geralmente este fundo está recoberto por uma camada de pus fluido, amarelo, não fetido. A ulcera, que como dissemos é ovalar, tem o seu diametro maximo de $3 \mathrm{cms}$ : transversalmente mede $2 \mathrm{cms}$. $\mathrm{O}$ grande eixo segue a direção da arcada crural, sobre a qual está implantada.

A base da ulcera c ligeiramente infiltrada. $O$ contorno pouco colorido, de um vermelho violaceo. Não é doloroza á palpação.

\section{C - EXAME COMPLEMENTARES}

1) Reação de Wassermann: (31-12-33) negativa

I1) Exame de urina: (12-1-33)

ه fisico : côr : amarelo citrico

aspecto : transparente

cheiro: sui generis

sedimento : pouco

densidade : 1012

reação de tornasol : acida

> de alguns elementos patologicos: albumina, traços; assucar e acetona, não contem.

> microscopico: celulas epiteliaes, raros leucocitos, cristaes de oxalato de calcio.

(a) Dr. H. Cerruti.

III) Punção pleural: retirou-se 20 cc. de liquido pleural.

Reação de Rivalta : +

Culturas : em agar-agar, agar-acite, caldo simples: negativas. 
Citologia: frequentes leucocitos, alguns monocitos e polinucleares.

Inoculação em cobaia: sacrificado o cobaio, pela autopsia não observamos em suas visceras, lesão provocada por bacilos alcool-acido resistentes de коCH.

(a) Dr. H. Cerruti

IV) Exame ds féses para pesquiza de ovos de parasitos :

a) pesquiza direta : negativa

b) processo de enrriquecimento de WILLIS : ovos de Tenia.

V) Reação de Ito-Reenstierna: negativa

VI) Reação de Frei : com 2 antigenos heterologos diverśos, francamente positiva. Houve formação de papula exuberante que pustulizou em seguida.

» $\gg$ Com antigeno homologo + , no paciente e em linfogranulomatosos comprovados.

VII) Exame radiologico: Pulmões -

Ausencia de lesão do parenquima pulmonar. Transparencia pleuro pulmonar normal :

(a) Dr. C. Campos $23 / 1 / 33$

\section{D - EVOLUÇÃo E TRATAMENTO}

Em 28-12-33 fez 1.a injeção de tartaro emetico.

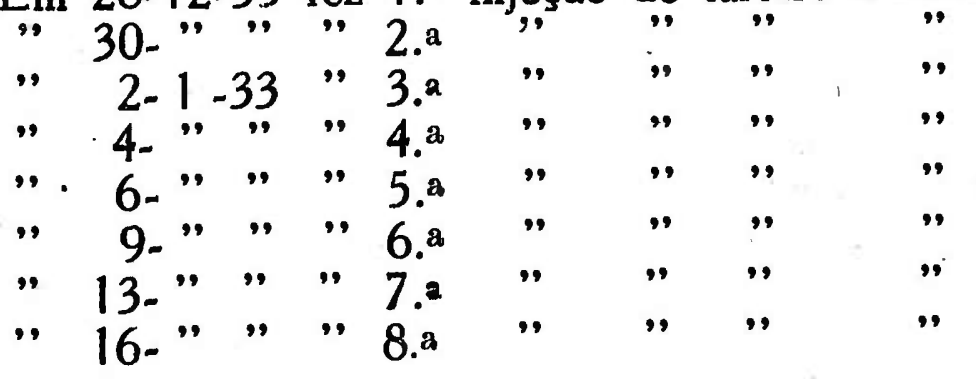

Neste data o doente ia bem, quanto á adenite, queixava-se porem, de dôres no hipocondrio esquerdo que o impediam de tossir, rir, etc... $\mathrm{O}$ exame praticado, revelou a existencia de atritos pleuraes na metade esquerda de tal hemitorax.

Em 17-1-33, suspendeu-se o tartaro emetico (depois da 8.a injeção), devido aos fenomenos pleuro-pulmonares : atritos pleuraes, sub-maciez da base, com diminuição do fremito (hemitorax esquerdo). Pedimos radiografia do torax (veja relatorio nos "exames complementares" desta observação). 
Em 20-1-33. Praticamos punção pleural esquerda obtendo liquido citrino, muito claro. Rivalta +. (V. em "Exames Complementares" os demais exames praticados).

Em 23-1-33 acusa diminuição das dôres. Teve vertigens, suóres frios. Está muito fraco, com grande inapetencia. Quanto a adenite, vae na mesma. Prescrevemos tintura de noz vomica $10 \mathrm{cc}, 5$ gotas antes do almoço e do jantar, para combater a anorexia. Temperatura em ascensão.

Em 30-1-33 Queixa-se de fortes dôres nas duas articulaçọes tibio-tarcicas.

Não se nota aumento de volume das articulações. lhos.

Em 31-1-33: Resolvemos fazer aplicação de raios infra-verme-

Em 2-2 - 33: Hoje aadenite está consideravelmente melhor : infartamento menor. Não ha pús mesmo á pressão. Orificios de abertura das fistulas cicatrizados. A marcha desentravada. A melhora obtida com os raios infra vermelhos foi consideravel com 3 aplicaçðes apenas.

Em 4-2 - 33 : Nosso exame revelou derrame pleural aumentado. Aumentaram - se as dôres do hemitorax esquerdo.

Em 8-2-33: Continuam fortes as dôres toraxicas. Persiste sem modificação o derrame, o tumor reduziu mais o seu volume.

Em 17-3-33: Fez 30 aplicações de raios infra vermelhos. Estado geral otimo. Não se queixa de nada. Aumentou $2 \mathrm{kgs}, 5$ de peso. Tumor consideravelmente diminuido. Completa cicatrização dos orificios fistulozos. As fotografias anexas mostram o estado do paciente antes e depois do tratamento. A. M. -22 anos $-\underset{*}{\text { Branco }}$ - Solteiro - Portuguez - moto-
rista - Residente em S. Paulo.

\section{A) - ANAMNESE}

Queixa: Adenite inguinal direita.

Molestia atual - Conta que se iniciou pelo aparecimento de um nodulo das dimensões de uma amendôa na região inguinal direita, no terço intèrno da arcada crural. Dolorozo, principalmente á pressão, em 20 dias atingiu o auge de seu volume, aumentando-se as dôres, calôr e rubor, com o crecimento. Teve coito suspeito 15 dias antes do aparecimento da adenite. Relata ter tido uma ferida no prepucio, que recobre a metade do corpo do penis, na região correspondente á face inferior da verga. Alem desta, apresentaram-se 5 outras, todas localizadas no prepucio, com os mesmos caracteres da primeira, porem de dimensões diversas. $O$ doente atribue serem causadas pela 1.a "ferida" descrita, pois tiveram aparecimento posterior e caracteres identicos. 


\section{Revista de Medicina}

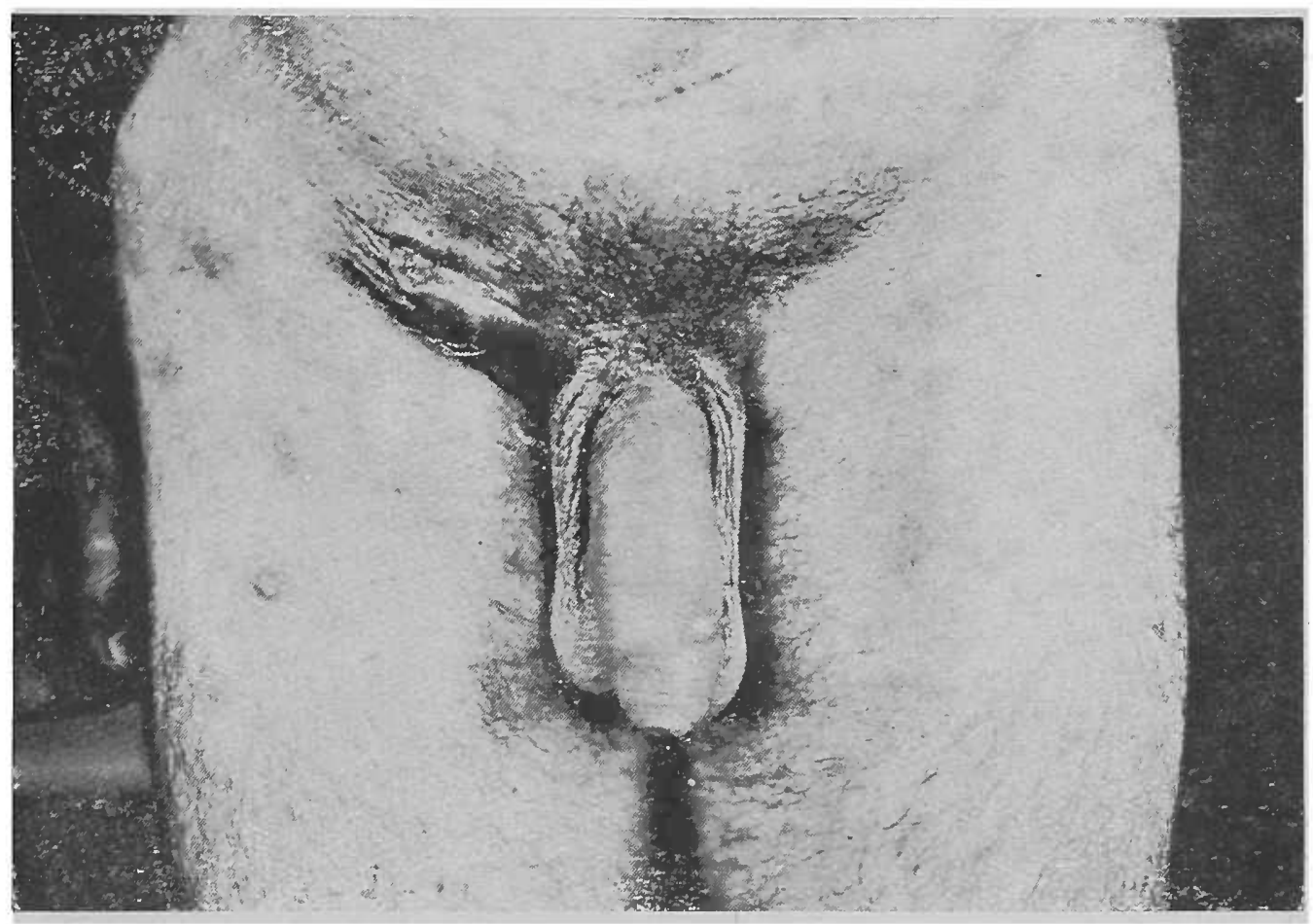

Fig. 3 - Fotografia em 3-2-33 : mostra tumor da região inguinal direita com a incisão que fora praticada, antes do doente nos procurar, ainda aberta, supurando abundantemente.

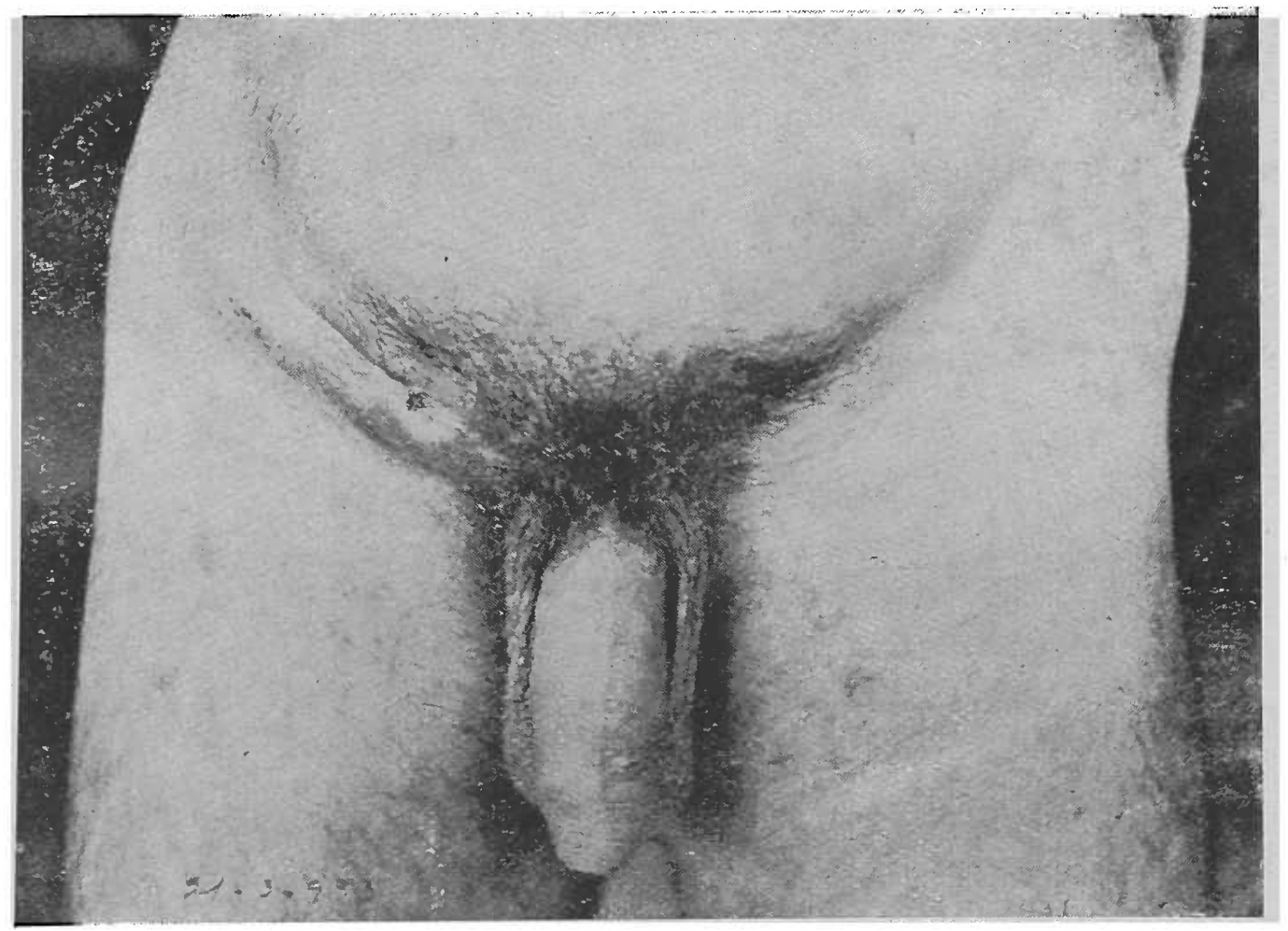

Fig. 4 - Fotografia em 21-3-33 - Tumor diminuido, completa cicatrização dos orificios fístulosos e incisão operatoria. 

As cicatrizes têm bordos regulares, fundo escavado e avermelhado. Fez tratamento local com lavagens de permanganato de potassio e pulverisação de um pó, que pelos caracteres descritos, parece ser o iodoformio.

A adenite, que como dissemos, teve sua evolução em 20 dias, foi após 30 dias incizada no Ambulatorio de Cirurgia da Santa Casa que o doente procurou.

Não notando melhora, o paciente foi a nós encaminhado pelo nosso colega, D.do Paulo de Campos Toledo.

Antecedentes pessoais: Gonorréa há 1 ano. Curou-se. Cancros referidos na molestia atual.

Antecedentes familiares hereditarios: sem interesse.

$$
\text { B) - EXAME OBJECTIVO }
$$

Exame de aparelhos, sistemas, orgãos e regiões.

Regiấo inguinal: Nota-se um tumor no $1 / 3$ interno da arcada crural. A pele da regiáo é de coloração violacea, distendida, apresentando duas fistulas lineares. Uma, mais ou menos na altura do bordo superior, outro na do inferior da arcada. Essas fistulas se iniciam pela sua extremidade interna; a superior a 2 dedos para fóra da espinha do pubis; a inferior a 3 dedos para fóra e para baixo do mesmo ponto e se dirigem para fóra seguindo a direç̧ão da arcada crural: apresentam mais ou menos $3 \mathrm{cms}$. de comprimento e deixam vazar, grande quantidade de materia purulenta, pouco fluida, amarelada.

A pele adéré á uma massa ganglionar, das dimensões de um limão, dura apresentando alguns pontos de amolecimento. A região inguinal direita não é do loroza á palpação.

A região inguinal esquerda apresenta ganglios infartados, duros, não dolorozos, desliżando sob a pele.

\section{C) - EXAMES COMPLEMENTARES}

I) Reação de FREI : + (23/12/32)

II) $O$ antigeno preparado com pús extraido por punção dos ganglios doentes, reagiu no paciente e em linfogranulomatosos comprovados.

III) Reação de Wassermann : sem reativação (21/12/32): negativa. $\gg \quad \Rightarrow \quad$ com reativação $(12 / 1 / 33):$ negativa.
$(22 / 2 / 33):$ negativa.

IV) Exame de féses para pesquiza de ovos de parasitos:

a) exame direto: negativo

b) processo de enriquecimento de Willis: + para ovos de Ascaris. 
V) Contagem global e especifica:

1..$^{\circ}$ Contagem global: $\left\{\begin{array}{r}\text { Eritrocitos : } 4.205 .000 \mathrm{~mm} 3 \\ 8.750 \mathrm{~mm}\end{array}\right.$

2. $\left.{ }^{\circ}\right)$ Dosagem de hemoglobina pelo metodo de Dare:

a) Riqueza da hemoglobina em relação com a do sangue normal ...................... $66 \%$

b) Riqueza do sangue em peso absoluto de hemoglobina: 92,40 grs. por litro de sangue.

3..$^{\circ}$ Capacidade de fixação do oxigenio: $13,38 \mathrm{cms}$. cc de oxigenio por cento de sangue.

4.) Relação globular: 1 para 480

5..$^{\circ}$ Riqueza globular: 3.623 .000

$\left.6^{\circ}\right)$ Valôr ou indice globular :...0,86

7..$^{\circ}$ Contagem diferencial dos globulos brancos:

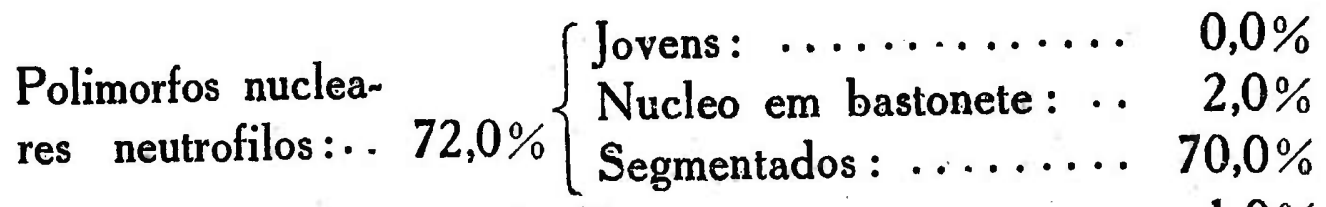

Polimorfos nucleares eusinofilos $. \ldots \ldots \ldots \ldots \ldots \ldots \ldots, 1,0 \%$

Polimorfos nucleares basofilos:............. $0,0 \%$

Linfocitos : $23,5 \% .\left\{\begin{array}{l}\text { Linfocitos leucocitoides..... } 18,5 \% \\ \text { Linfocito }\end{array}\right.$

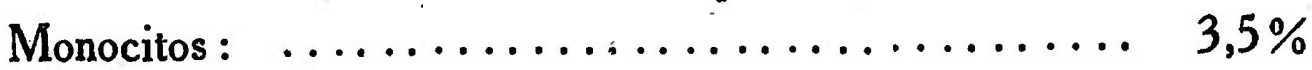

8..$^{\circ}$ Indice do desvio dos neutrofilos de Schilling 0,028. (Normalmente : 0,063).

(a.) Dr. H. Cerruti

\section{D) - EVOLUÇÃo E TRATAMENTO}

A. M, fez antes de nos procurar tratamento bismutico.

Sob os nossos cuidados; iniciou o tratamento pela "Fuadina" em 26/12/33.

Em 14/1/33: o doente se nos apresentou, com as fistulas quasi cicatrizadas, tumor diminuido de volume, não havia dôr e a coloração da pele tendendo á normal. Havia feito 9 injecções de "Fuadina".

Em $17 / 1 / 33$, após 11 injeç̧ões queixava se peor, com efeito : o nosso exame constatou fistulas abertas, grande tumor, ocupando $\circ 1 / 3$ 
interno da arcada crural, parte superior da região inguino-crural e inferior da região inguino-abdominal. A pele que recobre está rubefeita. $\mathrm{Ha}$ dôr e calor. Edema do prepucio.

$\mathrm{O}$ eritema pareceu-nos toxico ; de fato, indagado, o paciente refere-se a aplicação local de "Agua fagedenica". Alem disto, fez grandes esforços, lavando casa na vespera.

$E_{m} 20 / 1 / 33$. Tomou 13 injeções, apresentou-se já em melhores condições, desapareceu o eritema que circunscrivia o tumor, ficando o rubor localizado exclusivamente a este. A supuração ainda é abundante embora, a tumefação ganglionar tenha se reduzido.

Em 22/1/33: fez 14 infecções de "Fuadina", pouco melhorou, permaneceu aparentemente o mesmo, o estado local. Desde a 6. ${ }^{2}$ injecção queixou-se de fortes dôres articulares, que se agravaram sucessivamente, nos fazendo abandonar esse antimonial.

Suspendemos a medicação por alguns dias. $O$ paciente sentiu o seu estado geral peiorado, supuração aumentada. Resolvemos, então proceder : a) o exame do pús, em esfregaços corados pelos metodos de Gram Leishman, Ziehl-Nelson, sendo negativos; b) a inoculação em cobaio, 10-2-33 : Sacrificado o cobaio, a autopsia, não revelou lesões occasionadas pelos bacilos alcol-acidos resistentes de Koch (13-3-1933); c) colhemos pús para preparação do antigeno de Frei. d) Biopsia. Foi retirado um fragmento de ganglio, fixado pelo formol a $10 \%$. Corte corado pela hematoxilina e eosina. Fornecemos o mesmo córte a tres histopatologistas e pedimos suas opinioes. Eil-as:

Prof. Halberfeld: Tuberculose ganglionar.

\Carmo Lordy : Goma sifilitica ganglionar

Dr. Moacyr Amorim : Necrose de caseificação ganglionar de natureza sifilitica ou tuberculosa.

O mesmo bloco forneceu córtes que foram corados pelo Ziehl-Nelson e impregnados pela prata (metodo Levaditi), sendo negativos os resultados para a pesquiza respectivamente de bacilos de Koch e Treponema pallidum.

Em 8/3/33: Fizemos a 1.a aplicação de raios infra-vermelhos.

Em 11/2/33: Internamos o doente na $3 \mathrm{M}$. H, após ter feito já, tres aplicações. $\mathrm{O}$ estado geral continua o mesmo anterior. A adenite vae mal: entravando a marcha, tumor dolorozo, volumoso, supurando muito.

Perseveramos com os raios infra-vermelhos e os resultados no fim de 18 aplicaçðes não foram sensiveis.

Resolvemos então associar, o iodureto de sodio a $10 \%$, em injeções endovenosas trisemanaes, aos raios infra-vermelhos (1-3-33).

Teve melhoras desde a primeira injeção.

Em 18/3/33: Já fez 29 aplicaçóes de raio infra-vermelhos e 6 injeçбes de iodureto de sodio : o tumor reduziu consideravelmente de 
volume, não é mais dolorozo á palpação, supuração cessou, fistulas cicatrizadas, pele que recobre de tonalidade violacea.

\section{DIAGNOSTICO DIFERENCIAL DA DOENÇA DE NICOLAS E FAVRE COM OS TUMORES DA REGIÃO INGUINAL}

$\mathrm{O}$ quadro abaixo mostra os diversos tumores da regiáo inguinal com os quaes é necessario se fazer o diagnostico diferencial da doença de Nicolas e Favre nas suas diferentes fases.

Diagnose diferencial da linfogramulomatose inguinal sub aguda, com os :
I. Tumores solidos

$$
\begin{gathered}
\text { a) - epiplocéle } \\
\text { aderente }
\end{gathered} \quad\left\{\begin{array}{c}
\text { inguinal ou } \\
\text { crural }
\end{array}\right.
$$
da reg. ing. - crural.

b) - lipoma da verilha

$$
\text { c) - tumores malignos }\left\{\begin{array}{l}
\text { sarcoma } \\
\text { condroma }
\end{array}\right.
$$

$$
\begin{aligned}
& \text { II Tumo- } \\
& \text { A) Fecha- } \\
& \text { (a) - abcessos ossifluentes } \\
& \text { b) - Kistos das verilhas }\left\{\begin{array}{l}
\text { seboceos } \\
\text { hidaticos }
\end{array}\right. \\
& \text { a)-tuberculose dos ganglios }
\end{aligned}
$$


Do quadro que acabamos de vêr nos interessa para a diagnose diferencial somente os tumores abertos, fistulizados (os casos a que nos referimos estão nestas condições).

Vejamos então cada uma das entidades morbidas figuradas, separadamente :

a) Com a tuberculose dos ganglios inguinaes: A doença de $\mathrm{Ni}$ colas-Favre, pelo seu carater sub-agudo, torpido, pouco dolorozo, acarretando estado sub febril, perda de apetite, e o emagrecimento do paciente; pela sua grande tendencia á fistulização e sua semelhança hispatologica com a tuberculose ganglionar, pode ser facilmente confundida com esta ultima.

Esta semelhança anatomo-patologica é tão aparente que ainda hoje certos autores como, Bejarano, Covisa, Gay, Prieto consideram a linfogranulomatose inguinal de natureza tuberculosa, apezar deles propios sempre haverem obtido negativos todos exames bacteriologicos e todas as provas de inoculação em cobaios. Esses autores acreditam tratar-se de uma tuberculide ganglionar e justificam a sua opinião com a analogia das condições e existentes na tuberculide cutanea.

Marion e Gandy, baseados principalmente na presença de celulas gigantes nas cortes dos ganglios afetados e no fato de numa - das muitas inoculações que fizeram em cabras - encontrar no figado um nodulozinho, que pelo exame histopatologico, revelou a presença de celulas gigantes, sem contudo encontrar B. de Kock, atribuiram como causa a tuberculose.

Outros autores (Gamna, etc.) que tentaram a pesq. de B. Kock no puz e em cortes, obtiveram sempre resultados negativos. As cuti-reações á tuberculina, sempre negativas mesmo quando o molestia superada, afastando assim a possibilidade de um estado de anergia durante a molestia.

Por outro lado, Nicolas, Durand, Favre, Ramel e outros acham patognomonico o aspecto anatomo-patologico da linfogranulamatose inguinal sub-aguda.

Hellerström discorda dessa opinião, lembrando os casos da presença simultanea da infecção secundaria, nas quaes a tuberculose ganglionar, além de apresentar grande semelhança clinica com os estados mais adiantados de linfogranulomatose, mostra aspetos histologicos perfeitamente confundiveis.

Poderemos fazer a diagnose diferencial atendendo as seguintes considerações: a') As reações do paciente á tuberculina e ao antigeno linfogranulomatoso. Consideramos a reação de Frei patognomonica da molestia de Nicolas-Favre; b') Devemos considerar a evolução clinica da doença, sua localisação exclusiva na virilha, que não é a sede de predileção das adenites tuberculosas; a ausencia de adenopatias de outra natureza em outra regiões (axila, pescoço), uma vez que a tuberculose costuma ser multiganglionar; a supuração em pequenos fo- 
cos, pois a adenite tuberculosa supura na totalidade. c') Além disto, a peri-adenite dos ganglios tuberculosos não têm jamais a consistencia fibrosa e forte que a mesma apresenta na linfogranulomatose. d') $\mathrm{O}$ estado geral, relativamente bom do, paciente, o estado febril transitorio a ausencia de qualquer antecedente tuberculoso, a imagem radiografica normal dos pulmões de um linfogranulomatoso, completarão a nossa impressão clinica do caso. e) A inoculação em cobaios e outros animaes sensiveis trará tambem seu depoimento final.

\section{b) Diagnostico diferencial com a Sifilis.}

Um diagnostico, dificil é com a sifilis, principalmente com a sua forma de adenite gomosa :

Com efeito :

'a) A adenopatia primaria da sifilis é sempre acompanhada ou precedida do acidente inicial que a determinou. Si é verdade que esse acidente nem sempre possa ser percebido pelo paciente, ou pelo medico, (bubão "d'amblé" de Andry), não é menos verdade que essa adenite se apresenta tão caracteristicamente como descreveu Ricord. Não pode portanto ser nosso objeto de cogitação o fato em questão.

b') A adenopatia secundaria com o seu carater universal, está fora de discussão.

c') $O$ mesmo não se dá porem, com o linfogranuloma da lues terciaria, cujo aparecimento sem porta de entrada aparente, ás vezes acompanhado de ligeira reação febril; a positividade nem sempre constante das reaçбes serologicas nestas formas de lues; pelo contrario a positividade das mesmas reaçōes, ás vezes, na molestia de $\mathrm{Ni}$ colas-Favre ;

a similhança de liquido aspirado dos ganglios doentes; a dificuldade de se constatar a presença de treponemas em pesquiza local ; a inespecificidade do exame do pús pela infecção secundaria estando o foco aberto; a falta de conhecimento, ou inespecificidade do aspecto histopatologico da molestia de Nicolas-Favre, nesta fase muito dificultam senão mesmo impossibilitam o diagnostico diferencial.

Acrece a isso, como bem dizem Henke e Lubarsh "nosso conhecimento da histologia da adenite siiflitica é muito diminuto para permitir realmente uma diagnose diferencial".

Essa dificuldade tâo grande de diagnostico devido a semelhança tão estreita dessas duas formas de linfogranuloma levaram alguns autores mesmo a não acreditarem na individualidade morbida descrita por Nicolas-Favre e atribuirem a lues como causa; outros, crêm na associação frequente dessas duas formas, dando o aspecto clinico, anatomapatologico tão semelhantes.

Seja como tor, Hellerstróm deteve a maioria dos seus doentes, por varios mezes em clinicas especialisadas sem que fosse possivel desco- 
brir qualquer sinal de lues. A reação de Wassermann, ainda que repetida com longos intervalos, foi sempre negativa.

O mesmo autor verificou que a intradermo-reação á luetina (extrato fenicado de culturas de Treponema palidum, segundo a tecnica de Noguchi) apresentava-se negativa nos varios casos experimentados.

Esta reação têm algum valor na diagnose, pois como sabemos, a alergia cutanea aparece quando o micro-parasito começa a ser abatido pelo poder defensivo gradualmente adquirido pelo hospedador ou devido a uma terapeutica eficiciente do mesmo modo que nos velhos estados da doença e na sifilis hereditaria.

Hellerström jamais encontrou Treponemas no material extraido dos bubões e na substancia ganglionar extirpada, nem observou sintomas de lues nos animaes inoculados com esta ultima ainda mesmo quando fez inoculações intratesticulares no coelho. Enfim afirma a necessidade de novos estudos histologicos das respectivas doenças em cujos diagnosticos tenham sido feitos o mais exatamente possivel.

A intra-dermo reação de Frei resultou sempre negativa em todos os sifiliticos inoculados com os nossos antigenos.

Alem disso, pode-se excluir a sifilis, pela anamenese pelo exame objectivo.

$\mathrm{O}$ aparecimento do sifiloma inicial em casos de doença de Nicolas e Favre (casos de Spilmann, Drout e Michon), pode até certo ponto, excluir a lues, por ser relativamente raros os casos de cancros "redux". Quero me referir aos casos de recidiva "in loco". Pode acontecer o aparecimento de um $20^{\circ}$ cancro com localização diversa do $10^{\circ}$ (pseudo cancro sifilitico). Ha ainda a possibilidade de uma sobre infeção.

\section{c) Diagnostico diferencial com o Bubão Pestoso.}

E muitas vezes dificil distinguir as duas entidades morbidas, principalmente nos paizes em que a peste é endemica, onde se encontram fórmas atenuadas e ambulatorias chamadas "pestis minor", que Cantlie, Koch e outros, identificaram ao bubão climatico: há o entumecimento das verilhas e leve curva febril.

Todavia, a peste é geralmente uma doença agúda e rapida e o bubão pestoso não costuma apresentar focos multiplos e sucessivos de supuração.

$O$ aspecto histopatologico do bubão pestoso é inteiramente diverso do da linfogranulomatose: "numerosas celulas retrateis "de Recklinghausen e ausencia ou grande escassez de plasmazellen."

Quando não é possivel distinguir praticamente, trata-se de evidenciar a presença dos bacilos de Yersin ou recorrer-se á sôro-aglutina€̧ão. Algumas experiencias mostram reação de Frei negativa em varios casos de peste bubonica. 


\section{d) Diagnostico diferencial com as Adenites Gonococicas.}

Estas são pouco frequentes, raramente supuram e as vezes podem ser confundidas com as da linfogranulomatose inguinal.

Quanto ao aspecto histologico da linfadenite gonocociea, muito pouco se sabe a respeito. Sternberg dá uma descrição que em alguns pontos muitos se confundem com a molestia de Nicolas-Favre.

Para Gamna "as lesões histologicas e os caracteres do puz não concordariam, com a hipotese da origem gonococica. Nem foi encontrado o Gonocucus no puz.

Nós, que temos examinado sistematicamente o puz ganglionar e o corrimento uretral, jamais encontramos Gonococus.

Em caso de duvida, deve-se procurar a Neisseria gonorrheae no liquido extraído pelo punção dos ganglios ou no corrimento uretral, se houver. A reação de Frei resultou sempre negativa em todos os portadores de gonococías que tivemos oportunidade de inocular.

e) Diagnostico diferencial com a adenite do cancro mole.

"O exame histologico nos leva a alguma duvida : em um periodo precoce, falta de fato a exsudação leucocitaria ; mais tarde tambem, se esta existe, encontram-se os produtos nodulares caracteristicos que descrevemos".

"Analogas considerações valem pela opinião sustentada por Milian, Gourgerot, que se trate de uma infecção de B. de Ducrey".

Estes porem nunca foram encontrados na lesão. Na linfogranulomatose não há auto-inoculação, ha ausencia absoluta de fagedenismo, e da adenite iliaca interna.

Por outro lado Cappelli, pretende demonstrar serem as lesões iniciaes diferentes da do cancro venereo. O mesmo para Bory (cancro linfogranulomatoso).

Alem disso, no cancro mole, o processo é mais agudo, o tumor dentro em pouco se torna muito mole e recoberta por uma pele adelgaçada ; é dolorozo e em geral, forma-se uma só cavidade e um só orificio fistular fagedenico, pelo qual escorre pus de côr chocolate. Entretanto este aspecto pode variar muito; ha casos em que alguns ganglios supuram e outros não (bubões "strumosos") originando fistulas multiplas, assumindo u'a marcha torpida, o que fará confundi-los com a linfogranulomatose.

Nos casos duvidosos a evidenciação dos bacilos de Ducrey, constitue a melhor prova, mas, como isso necessita de bastante tempo e trabalho, poder-se-ão usar na pratica as reações de Frei e de Ito-Reenstierna.

Esta ultima é feita com emulções homogeneas de culturas mortas de bacilos de Ducrey, dificeis de preparar. 
Os trabalhos de Heillerstrọm nesse sentido são muito eloquentes e autorizam a conclusões praticas : ele observou reação de Frei negativa em todos os casos de cancro mole que inoculou, emquanto que a reação intra-cutanea de Ito Reenstierna se mostrava indubitavelmente positiva; em todos os casos de linfogranulomatose inguinal aconteceu exatamente o inverso. Aos mesmos rezultados temos chegado, nos casos por nós observados: usamos para a pratica da reação de Ito-Reenstierna o "Dmelcos".

f) Diagnose diferencial com as adenites estafilo ou estreptococicas.

As adenites inflamatorias simples sucedem a uma lesão banal infectada da verga ou do anus ou então ás feridas banaes, as mais ou menos contaminadas, do pé e da perna (adenites cruraes). Via de regra o aspecto clinico destas ultimas é mais agudo, elas são muito mais dolorosas e amolecem muito mais rapidamente que a linfogranulomatose. Entretanto podem terminar por resolução sem amolecimento. Quanto ao aspecto histologico das adenites septicas, Hellerström demonstrou que não raramente ele é cofundivel com o da doença de Nicolas-Favre.

Deve-se então, procurar a presença de estafilo ou estreptococos no pus graglionar e ao mesmo tempo praticar a reação de Frei nos pacientes.

g) Diagnose diferencial com a actinomicose.

É muito rara a localisação da actinomicose nos ganglios inguinaes. Para distinguir estas formas linfadeniticas, a determinação do agente etiopatogenico (Actinomices) constituirá prova concludente.

h) Diagnose diferencial com o linfogranuloma coccidioidico.

Tambem esse raramente se localiza na região inguinal; alem disso, costuma atacar simultaneamente varias zonas ganglionares. A verificação microscopicas da presença de blastomicetos evitará seguramente a confusão.

$$
* *
$$

Seria possivel a diagnose diferencial dos casos apresentados, diante das considerações que acabamos de tecer?

Um, pelo seu carater sub-agudo, torpido, pouco dolorozo, estado sub-febril, perda de apetite, emagrecimento do paciente, fenomenos pleuraes, tendencia a fistulização; em muito se aproxima senão mesmo se confunde com a tuberculose.

Outro, pelo contrario se aproximando por determinadas razões a tuberculose, e por outras á sifilis.

Senão, recordemos resumidamente as observaçóes dos casos: 
$10^{\circ}$ caso: S. A. L, portador de uma adenite inguinal direita, supurada, datando de 2 mezes e 7 dias. Atingiu as dimensóes maximas em 20 dias. Supurou e fistulizou em 30 dando saída a pus amarelado, crêmoso.

Não fez tratamento algum.

Procurou-nos em 26/12/33. Relata ter tido de 1919, adenite bilateral, supurada, sem lesão inicial, de decurso sub-agudo, semelhente a atual. Gonorréa em 1923, curou-se; antecedentes sifiliticos, estigmas de lues hereditaria e reação de Wassermann negativos. Estado geral abatido tendo emagrecido $3 \mathrm{kgs}$. e 1/2 da data da infecção. A partir de 16/1/33 (ou sejam 20 dias após a consulta, após ter tomado 8 injecções de tartaro hemetico), queixou-se de dôres no hemitorax esquerdo que o empediam tossir, rir, etc. $O$ exame revelou a existencia de atritos pleuraes em tal hemitorax. Sentiu-se tomado de grande fraqueza, inapetencia, suôres frios e vertigens. Temperatura em ascenção.

Diante do quadro descrito trata-se de um caso de tuberculose ganglionar com localização inguịnal, ou da molestia de Nicolas-Favre?

Somos pela segunda hipotese:

apezar da ambiguidade do estado geral do paciente;

apezar da localização da adenite;

apezar da ausencia de adenopatias em outras regiões não serem provas concludentes;

apezar da inoculação em cobaios negativa, não ser argumento para autores da valia de Bejerano, Coviza, Gay, Prieto, julgamos elementos altamente valiosos para o diagnostico, dos nosso caso:

a) a imagem radiologica normal dos pulmões

b) a negatividade dos exames do liquido pleural

c) a negatividade da inoculação em cobaios com liquido pleural

d) a positividade da reação de Frei com antigenos homologos e heterologos

Com efeito: a reação de Frei foi francamente positiva com 2 antigenos diversos, A sua especificidade não pode ser posta em duvida, até a hora presente (naturalmente desde que se tenham as precauçces necessarias). Mas não se pode tambem, por em duvida, a positividade desta reação mesmo muitos anos após a infecção (até 24 anos segundo a observação de Salomão Fiquene). Ora, o nosso paciente relata em 1919 ou seja há 14 anos passados, uma adenite supurada de decurso sub-agudo, sem lesão inicial. Isso podia nos levar a supor que a reação de Frei com a sua positividade corresse por conta dessa adenite, perdendo assim, todo o seu valor para o diagnostico da adenite atual.

$20^{\circ}$ caso: A. M.: queixa-se de adenite inguinal direita supurada, iniciando-se por um nodulo das dimensóes de uma amendôa, pouco dolorozo á pressão, atingindo o maximo de dimensões em 20 diaś, com aumento de dôr e aparecimento de calôr e rubôr. 
Teve coito impuro 15 dias antes da molestia, relatando ferida no penis. As cicatrizes são recentes sem carater tipico. No fim de 30 dias a adenite foi incizada, não obtendo melhoras. Antes de nos procurar: fez ainda tratamento bismutico, sem resultado.

Aos nossos cuidados: Fuadina, (14 injeções) Intolerancia, sem resultado; $\mathrm{NaI}+$ raios- infra-vermelhos. Melhora na $1 . .^{\text {a }}$ injeção de iodeto de sodio. Cicatrização na 6.a (cura sem recidiva). Gonorréa há 1 ano.

O exame da região direita revelou: tumor do $1 / 3$ interno da arcada crural direita. Pele violacea, distendida, apresentando fistulas, que vasam materia purulenta fluida amarelada.

$A$ região inguinal esquerda, apresenta ganglios infariados durros não dolorozos deslizando sobre a pele.

Antecedentes sifiliticos, estigmas de lues hereditaria e reação de Wassermann praticada por tres vezes espeçadamente, com e sem reativação biologica: negativos.

Para os 2 casos lançamos mão de um argumento, que a nosso vêr é "tranchant", puncionando um dos ganglios supurados dos pacientes, preparando o antigeno, que reagiu em linfogranulomatosos comprovados, comportando-se inativamente com os testemunhos. 